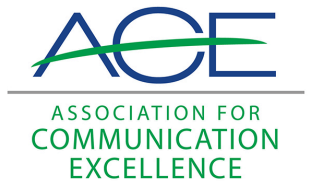

Journal of Applied Communications

\title{
Looking for Information: An Exploratory Analysis to Explain Public Information-Seeking Behaviors About Mosquito Control
}

Shelli D. Rampold

University of Florida

Melissa Cater

Louisiana State University

Ricky W. Telg

University of Florida

Follow this and additional works at: https://newprairiepress.org/jac

Part of the Communication Technology and New Media Commons, Education Commons, Health Communication Commons, Organizational Communication Commons, and the Public Relations and Advertising Commons

(c) (1) (9)

This work is licensed under a Creative Commons Attribution-Noncommercial-Share Alike 4.0 License.

\section{Recommended Citation}

Rampold, Shelli D.; Cater, Melissa; and Telg, Ricky W. (2020) "Looking for Information: An Exploratory Analysis to Explain Public Information-Seeking Behaviors About Mosquito Control," Journal of Applied Communications: Vol. 104: Iss. 3. https://doi.org/10.4148/1051-0834.2329

This Research is brought to you for free and open access by New Prairie Press. It has been accepted for inclusion in Journal of Applied Communications by an authorized administrator of New Prairie Press. For more information, please contact cads@k-state.edu. 


\title{
Looking for Information: An Exploratory Analysis to Explain Public Information- Seeking Behaviors About Mosquito Control
}

\begin{abstract}
Mosquitoes pose substantial risks in communities worldwide, and the extent and type of such risk may vary across communities and regions. The integrated mosquito management approach integrates multidisciplinary methods into practical strategies tailored to local communities. Reduction of mosquito larval sources via community engagement in at-home mosquito control behaviors is a key component of this approach. Best methods of communicating information to the public to foster knowledge and motivation to engage in local mosquito control efforts. The purpose of this descriptional, correlational study was to describe the Florida public's mosquito control information search behaviors, as well as examine factors that may explain those behaviors. Findings revealed statistically significant relationships existed between respondents' information search frequency and their subjective and objective knowledge, importance of mosquito control, personal responsibility, income and education. Significant relationships were also observed between personal responsibility and homeownership and type of residence. Respondents perceived CDC websites and Florida DOH websites as the most trustworthy of the sources listed, and were most likely to use local mosquito control program websites when searching information. Local mosquito control districts should use the findings of this study to target passive audiences and facilitate their future engagement in mosquito control dialogues. Future research is needed to further examine the directionality and predictive nature of variables examined in this study.
\end{abstract}

\section{Keywords}

Florida residents, information-seeking behaviors, mosquito control, science communication, personal responsibility

\section{Cover Page Footnote/Acknowledgements}

The Prevent \& Protect project was funded by a grant awarded by the Florida Department of Health.

\section{Erratum}

A previously published version of this article contained the wrong full-text manuscript. This has been corrected on July 6, 2021. 


\section{Looking for Information: An Exploratory Analysis to Explain Public Information-Seeking Behaviors About Mosquito Control}

\section{Introduction}

Mosquitoes pose substantial ecological, economic, and health risks in communities worldwide (Bodner et al., 2016; Healy et al., 2014). The type and extent of impact of such risks can vary significantly between communities (Association of State and Territorial Health Officials [ASTHO], 2018). Dense mosquito populations may heavily burden the local economies of communities that depend on outdoor recreation and tourism (Duman-Scheele et al., 2018) while other communities may be largely subject to increased health risks and care associated with mosquito-borne disease outbreaks (American Mosquito Control Association [AMCA], 2018b; ASTHO, 2018; World Health Organization [WHO], 2017).

Mosquito control needs also differ depending on the environmental conditions of a region. Areas, such as Florida, that are prone to hurricanes and flood-related disasters may experience drastic increases in mosquito populations following such events, which can increase the risk of exposing humans and animals to diseases and hinder recovery and cleanup efforts (ASTHO, 2018; Connelly, 2016). Differences in risks across regions thus require mosquito management plans tailored to the needs of the local community (ASTHO, 2018). As such, modern U.S. mosquito control programs utilize an integrated mosquito management (IMM) approach to develop mosquito control strategies according to the economic, ecological, and social needs of a community (AMCA, 2018a; U.S. Environmental Protection Agency [EPA], 2012).

IMM integrates multidisciplinary methods into practical and effective pest management strategies that often include both chemical applications and nonchemical methods (AMCA, 2018a; U.S. EPA, 2012). Chemical applications include those to control larvae (i.e., larvicides) and adult mosquitoes (i.e., adulticides), and they are primarily conducted after surveillance procedures reveal mosquito populations have exceeded the established population threshold (U.S. EPA, 2012). Unfortunately, chemical applications alone may not be sufficient in controlling urban or peridomestic mosquito populations (Bodner et al., 2016). Peridomestic mosquito species are those able to thrive in urban or suburban areas and, therefore, have close contact with and pose substantial threat to human populations (Fonseca et al., 2013). Controlling peridomestic mosquitoes via adulticiding can be costly for some mosquito control agencies, often raises public health and safety concerns due to the public visibility of many adulticide applications (e.g., aerial spraying), and can be ineffective in controlling mosquito species that are more active during times of the day when spray application methods are not preferred (Bodner et al., 2016; Fonseca et al., 2013; Rose, 2001).

The disease-vector peridomestic mosquito species common in North America typically complete their developmental life-stages from egg, larvae, to pupae in artificial water-holding containers (e.g., birdbaths, buckets, tires; Bodner et al., 2016). As such, rather than relying strictly on adulticides after population thresholds have been met, a central component of IMM is the active reduction of larval habitats (i.e., source reduction) to help control mosquito populations before mosquitoes emerge as adults (AMCA, 2018a; Rey \& Connelly, 2016; U.S. EPA, 2012). However, source reduction in urban and suburban areas can be difficult due to the need to access private residences. Community education and engagement is, therefore, critical to this component of IMM (Healy et al., 2014). 
Involving local community members in mosquito control efforts has long been considered a key contributor to short-term success and long-term sustainability based on the rationale that it is necessary to involve those responsible for the creation of container larval habitats in controlling or eliminating those habitats (Gubler \& Clark, 1996). This concept of a community-based, integrated approach to mosquito control is also supported by findings in prior research, in which resident-driven management of water-holding containers was identified as an effective and affordable means of reducing larval sources and controlling adult mosquito populations in an area (ASTHO, 2018; Bodner et al., 2016; Fonseca et al., 2013; Healy et al., 2014; Richards et al., 2008). However, resident-based mosquito management requires residents who are knowledgeable of and motivated to employ such practices (Bodner et al., 2016). Local mosquito control districts and health agencies must be able to conduct effective education and outreach programs to communicate evidence-based information to residents and facilitate their adoption of resident-based mosquito control behaviors (ASTHO, 2018; Bodner et al., 2016).

Science communication involves "the exchange of information and viewpoints about science to achieve a goal or objective, such as fostering greater understanding of science and scientific methods or gaining greater insight into diverse public views and concerns about the science related to a contentious issue" (National Academies of Sciences, Engineering, and Medicine [NASEM], 2016, p. 14). Depending on the context, there may be several goals for communicating science, such as presenting scientific findings, increasing knowledge and understanding related to a particular issue for which a decision is required, or influencing people's opinions and behaviors when scientific evidence indicates particular consequences (NASEM, 2016). Ezezika and Mabeya (2014) maintained effective science communication must go beyond the mere dissemination of scientific information to include strategies for establishing and fostering trust between scientists and end users. Strategies for fostering trust-centered communication may include providing clear and correct information, training stakeholders on how to communicate, establishing transparency, and creating awareness through early engagement with end users (Ezezika \& Mabeya, 2014). Early engagement with the public can help facilitate evidence-based decisions, foster transparency, and identify the targeted audiences' questions, concerns, and needs (NASEM, 2016).

While science communication involves more than the mere dissemination of information, public access to and attainment of essential information is necessary nevertheless. Public trust in the source of information is a key component of communicating science, and examining their perceived trustworthiness of sources can provide a more holistic understanding of their information search behaviors (Brewer \& Ley, 2013). In some prior studies, the public's trust in science and its institutions was a stronger predictor of their acceptance of scientific information about a topic than their knowledge about that topic (Priest et al., 2003). However, use and credibility of information vary across different users and environments (Brewer \& Ley, 2013; Robson \& Robinson, 2012). Determining best formats for communicating information to the public is thus dependent upon the content of the information and the audience for which the information is intended (American Association for the Advancement of Science [AAAS], 2017a; 2017b). Identifying the types of sources used and trusted by the public to gather information about mosquito control may provide a better understanding of their search behaviors and inform recommendations for how mosquito control and public health agency specialists can best communicate information to their audiences. 


\section{Conceptual Framework}

The goals of communicating science about mosquito control as framed in the current study are to foster public uptake of information needed to increase their knowledge and awareness of mosquito control in their communities and facilitate their engagement in resident-driven components of IMM. This communication goal requires, at the very least, active and positive information-seeking behaviors among targeted audiences (Robson \& Robinson, 2012). The public's information-seeking behaviors was the primary variable of interest in this study, and it was operationalized as how frequently the public had actively sought information about mosquitoes or mosquito control topics in the past year. A review of literature was conducted to develop a working conceptual framework for explaining this behavior. Per the proposed framework, the public's search frequency for information about mosquito control topics may be explained by their (a) objective and subjective knowledge of mosquitoes and mosquito control topics, (b) perceived importance of mosquito control, (c) sense of personal responsibility in controlling mosquito populations, and (c) demographic attributes, including educational attainment, income, home ownership, and type of residence (Case, 2007; Griffin et al., 1997; Johnson \& Tversky, 1983; National Science Board [NSB], 2016; Radecki \& Jaccard, 1995; Robson \& Robinson, 2012; see Figure 1).

\section{Figure 1}

Proposed Conceptual Model to Explain the Public's Mosquito Control Information-Seeking Behaviors

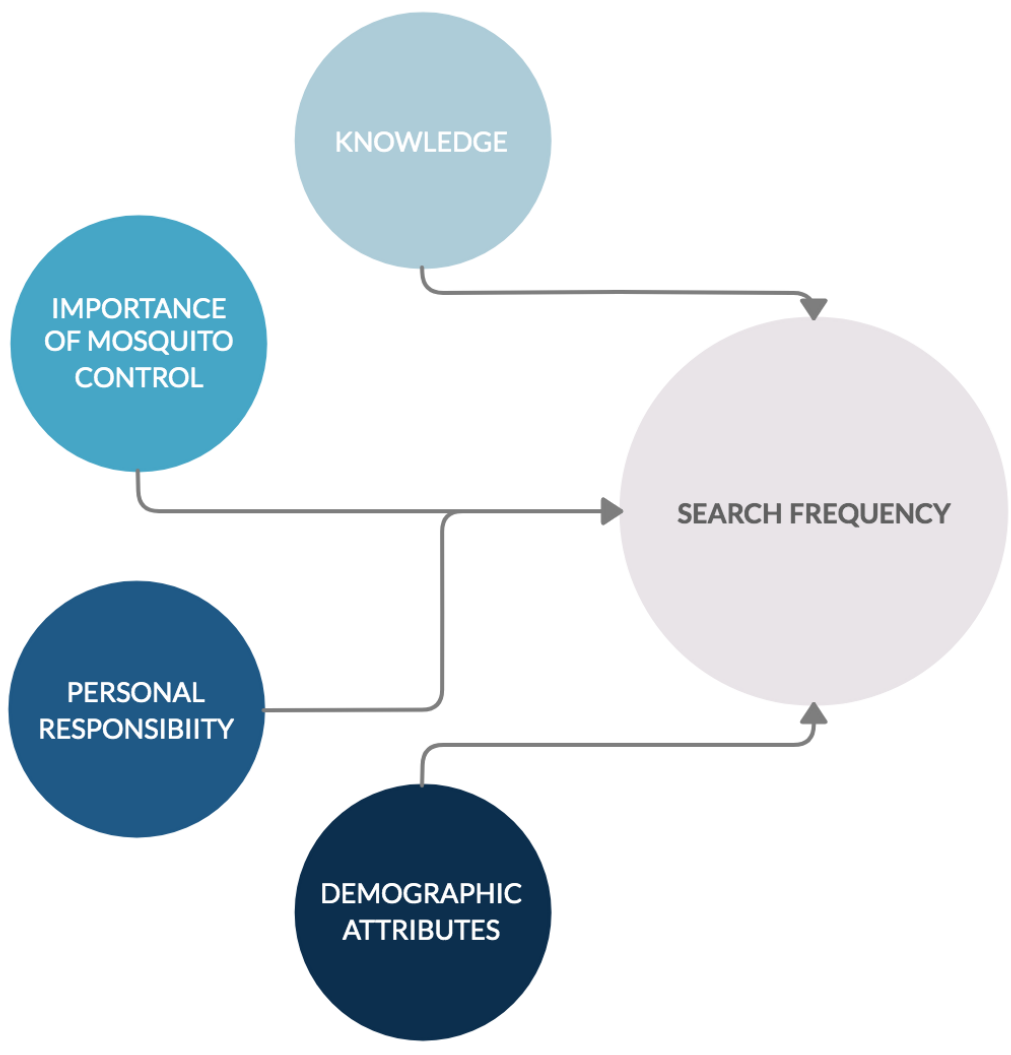




\section{Knowledge}

Information search behaviors can be influenced by an individual's perceived or actual knowledge of a topic (Case, 2007; Griffin et al., 1997; Robson \& Robinson, 2012). Griffen et al. (1997) proposed a model to predict an individual's risk information-seeking behaviors based on his or her personal characteristics. Per their proposed model, an individual's subjective knowledge and perceived importance or personal worry about a risk should manifest in their judgment regarding the amount of information needed to manage the outcome (Griffin et al., 1997). Similarly, Radecki and Jaccard (1995) found perceived knowledge to be both a predictor of information search behaviors and significantly correlated with objective knowledge. As such, both objective and subjective knowledge were included in the proposed conceptual model for this study to explain information search frequency.

\section{Perceived Importance and Personal Responsibility}

As individuals often seek information based on a felt or observed need (Case, 2007), perceived importance of an observed risk or personal responsibility felt in managing such risk may motivate an individual to seek the information needed to respond accordingly (Griffin et al., 1995; Robson \& Robinson, 2012). On the other hand, if an individual is not motivated to take personal action or address a felt need by seeking information, they may instead act on the basis of prior knowledge or experience (Robson \& Robinson, 2012).

\section{Personal Characteristics}

Demographics and personal characteristics are frequently examined across social sciences to explain variance in a particular behavior. The personal characteristics of interest in this study were (a) income, (b) education, (c) home ownership, and (d) type of residence. While the average person is tasked with making sense of scientific topics to make informed decisions, all persons do not have equal access to informational sources and formal education skills needed to interpret complex information (Takahashi \& Tandoc, 2016). In prior studies, income levels and educational attainment have not only been positively correlated with an individual's ability to understand scientific information, but also with their positive perceptions of scientific information in general (NSB, 2016). Due to the exploratory nature of this study, these demographic variables were included in the proposed conceptual model as independent influencers of information-search frequency. Home ownership may also directly or indirectly influence the public's information-seeking behaviors in that those who own their own home may feel greater personal control over employing at-home methods of mosquito control (Griffin et al., 1997), and thus be more likely to seek information about such methods. Type of residence may also explain the public's information-seeking behaviors about mosquito control. Measures of personal relevance, including prior experience with a risk or hazard, have been identified as significant predictors of whether an individual would seek out relevant information in the future (Case, 2007; Johnson \& Tversky, 1983; Radecki \& Jaccard, 1995; Robson \& Robinson, 2012). Residents who have home environments more conducive to mosquito breeding (i.e. a house with a yard) may perceive greater personal relevance of and a greater need for information about mosquito control (see Figure 1). 


\section{Purpose and Objectives}

This study was conducted as part of a larger project to design and evaluate an educational campaign about mosquito control. The Prevent \& Protect project was funded by the Florida Department of Health to develop an educational campaign and materials for mosquito control and public health agencies to use to enhance public education about such. The purpose of this descriptive, correlational study was to gain a better understanding of the public's information search behaviors regarding mosquito control topics, as well as the relationships between factors that may explain those behaviors, to provide practical recommendations for disseminating information and enhancing public knowledge. The findings of this study may also be transferrable to other topics that require effective communication of scientific information to public audiences. Three research objectives guided this study:

1. Describe the Florida public's information-seeking behaviors about mosquito control topics in terms of information search frequency, likeliness of use of information sources, and perceived trustworthiness of information sources;

2. Describe the Florida public's subjective and objective knowledge about mosquito/mosquito control topics;

3. Examine relationships between the Florida public's information search frequency and their subjective and objective knowledge, perceived importance of mosquito control, perceived personal responsibility for mosquito control, and personal characteristics.

\section{Methodology}

An online survey research design was utilized to address the research objectives of this study. The population of interest was Florida residents age 18 or older. A public opinion research company, Qualtrics, was consulted to obtain a non-probability opt-in sample of Florida residents representative of the state population based on the 2010 Census data. Non-probability sampling is an approach commonly used to make population estimates (Baker et al., 2013). This sampling method has become more common in research examining public opinion of emerging issues due to the increased access to internet, the relatively low cost of online surveys, higher response rates compared to probability-based methods commonly used in the past (e.g. random digit dialing of landline numbers), and overall greater ease of reaching members of the population of interest (Lamm \& Lamm, 2019). An initial pilot test of 50 respondents was conducted, and the pilot data for the scales were analyzed to ensure reliability. All scales were found to be reliable with a Cronbach's $\alpha>.76$. Therefore, no changes were made to the instrument before resuming data collection.

Through Qualtrics, respondents are recruited using traditional, actively managed market research panels and social media platforms. To help exclude duplication and ensure validity, Qualtrics also employs digital fingerprinting technology, IP address checks, and works with panel partners that also employ such methods to obtain non-probability opt-in samples in market research (Qualtrics, 2019). In this study, an online link to the survey questionnaire was distributed to a total of 1,503 Florida residents. Attention filters (e.g. "select strongly agree for this answer") were used to identify respondents not paying attention to the questions. Respondents who did not complete all items of the instrument, those who did not select the appropriate answer to attention filters, and those who did not fall within the parameters of being a Florida resident 18 years of age or older were excluded from analysis. Useable responses were 
obtained from 789 residents for a $52 \%$ response rate. Of the 789 cases, 500 were randomly selected for primary data analysis and served as the sample in this study. The remaining 289 cases were designated for instrument analysis.

Potential exclusion, selection, and non-participation biases can limit the use of nonprobability samples (Baker et al., 2013). Therefore, to alleviate such impacts, poststratification weighting methods (Kalton \& Flores-Cervantes, 2003) were executed post hoc. Such weighting methods have been found to yield results in non-probability opt-in samples comparable in standard to those obtained using probability-based samples (Twyman, 2008). Specifically, demographics were used to balance the results based on the 2010 Census data to ensure the sample reflected the adult population in Florida and to produce results intended to approximate the population of interest (Baker et al., 2013). Additional demographic information (e.g., political affiliation, income, education, etc.) was also collected to better describe respondents and ensure the sample was demographically representative of the population of interest.

\section{Population}

Respondents $(N=500)$ were primarily white $(f=388 ; 77.6 \%)$ and within the age range of 30 to $59(f=252 ; 50.6 \%)$. Slightly more respondents identified as female $(f=258 ; 51.7 \%)$ than male. More respondents fell within the income bracket range of $\$ 25,000$ to $\$ 49,999(f=156 ; 31.1 \%)$ than any other category, and had received a four-year college degree $(f=123 ; 24.6 \%)$ or high school diploma $(f=105 ; 20.9 \%)$ as their highest level of education completed. Regarding their political beliefs and affiliations, a larger number of respondents held moderate political beliefs $(f$ $=189 ; 37.8 \%)$ than any other category, and slightly more respondents were affiliated with the Democratic party $(f=186 ; 37.2 \%)$ than the Republican party $(f=170 ; 34.1 \%)$. Regarding place of residence, the majority of respondents lived in a house with a yard $(f=378 ; 75.5 \%)$, and more respondents owned their homes $(f=317 ; 63.3 \%)$ than rented. Full descriptive results for the variables included in the inferential analyses of this study are provided in Table 1.

\section{Table 1}

Demographic Characteristics of Respondents $(N=500)$

\begin{tabular}{lcc}
\hline Variable & $f$ & $\%$ \\
\hline Income $^{\text {a }}$ & & \\
$\quad$ Less than $\$ 24,999$ & 93 & 18.6 \\
$\$ 25,000$ to $\$ 49,999$ & 156 & 31.1 \\
$\$ 50,000$ to $\$ 74,999$ & 109 & 21.9 \\
$\$ 75,000$ to $\$ 149,999$ & 118 & 23.6 \\
$\$ 150,000$ to $\$ 249,999$ & 18 & 3.6 \\
$\$ 250,000$ or more & 5 & 1.1 \\
Education ${ }^{\text {b }}$ & & \\
${\text { Less than } 12^{\text {th }} \text { grade (did not graduate high school) }}_{\text {High school graduate (includes GED) }}$ & 10 & 2.0 \\
Some college, no degree & 105 & 20.9 \\
2-year college degree (Associates, Technical, etc.) & 99 & 19.7 \\
\end{tabular}




$\begin{array}{lcc}\text { 4-year college degree (Bachelor's, etc.) } & 123 & 24.6 \\ \quad \text { Graduate or professional degree } & 81 & 16.2 \\ \text { Home Ownership }{ }^{\text {c }} & 317 & 63.3 \\ \quad \text { Owns home } & 169 & 33.8 \\ \text { Rents home } & 13 & 2.6 \\ \quad \text { Other } & 378 & 75.5 \\ \text { Type of Residence d } & 68 & 13.6 \\ \quad \text { House with a yard } & 41 & 8.2 \\ \quad \text { Apartment with an outdoor patio/balcony } & 12 & 2.4 \\ \quad \text { Apartment with no outdoor patio/balcony } & \\ \text { House with no yard }\end{array}$

${ }^{a}$ Responses missing from 1 participant

${ }^{\mathrm{b}}$ Responses missing from 5 participants

${ }^{\mathrm{c}}$ Responses missing from 1 participant

${ }^{\mathrm{d}}$ Responses missing from 1 participant

\section{Instrument}

An original questionnaire designed by the researchers served as the instrument for this study. Face and content validity were established by an expert panel consisting of faculty and specialists from the University of Florida Department of Agricultural Education and Communication; Department of Family, Youth and Community Sciences; Department of Entomology and Nematology; Florida Department of Agriculture and Consumer Services; and the Centers for Disease Control and Prevention (CDC) Southeastern Center of Excellence in Vector Borne Diseases. The questionnaire was evaluated by the panel for readability, layout and style, clarity of wording, and accuracy of scientific content (Colton \& Covert, 2007). Content experts were also residents of Florida and were, therefore, able to provide feedback on how the targeted audience may interpret and respond to instrument items. Revisions were made to correct distractor options from multiple-choice knowledge assessment questions, and the panel deemed the instrument acceptable. Post hoc reliability estimates for the instrument's constructs, i.e., knowledge and importance of mosquito control, were calculated using Cronbach's alpha. To assess reliability of non-construct items (e.g. information search frequency and personal responsibility) a separate sample of 45 respondents was obtained for test-retest procedures. A shortened version of the instrument was administered to these respondents twice, with a threeweek interval between tests. Paired sample $t$-tests were employed to determine if statistically significant differences existed between respondents' pre- and post-test scores. Five sections of the instrument were used for primary data analysis in this study: (1) information-seeking behaviors, including source use, trustworthiness, and search frequency; (2) objective and subjective knowledge; (3) perceived importance of mosquito control; (4) personal responsibility for mosquito control; and (5) demographic characteristics including income, education, type of residence, and homeownership. 


\section{Information-seeking Behaviors}

Respondents' information-seeking behaviors were assessed in terms of how frequently they sought information about mosquitoes/mosquito control topics in the past year, how likely they would be to use select sources if they were to seek such information, and their perceived trustworthiness of those sources. A single item was used to assess information search frequency $(1=$ never; 2 = rarely, $1-2$ times; 3 =occasionally, 3-4 times; $4=$ often, $5-6$ times; $5=$ very often, more than 6 times). For source use, respondents were asked to indicate how likely they would be to use each of the fourteen sources provided (e.g. Department of Health websites) if they were to seek information about mosquito control topics. Responses were collected using a five-point Likert-type scale: 1 = very unlikely; 5 = very likely. Regarding source trustworthiness, respondents were asked to indicate how trustworthy they perceived those same sources to be as sources of information about mosquito control topics. Responses were collected using a 5-point Likert-type scale: 1 = very untrustworthy; 5 = very trustworthy. Test-retest reliability procedures revealed no significant differences between respondents' first and second test scores, $t(45)=-$ $1.31, p=.20$.

\section{Knowledge}

Two sections of the questionnaire were used to measure respondents' subjective (i.e. selfperceived) and objective (i.e. actual) knowledge of mosquito control topics. Respondents' objective knowledge of mosquito control topics (e.g. habitats in which mosquitoes can breed, mosquito-borne illnesses, methods of mosquito control) was assessed using 22 items with multiple choice or yes/no response options. Responses were recoded $(1=$ correct; $0=$ incorrect $)$, and a summated score of total correct answers was computed. Subjective knowledge was measured using nine items reflective of the learning objectives associated with the objective knowledge component of the instrument. Respondents were asked to indicate the degree to which they agreed with statements such as, "I am knowledgeable of the types of conditions that are ideal for mosquitoes to reproduce." Responses were collected using a six-point Likert-type scale: 1 = strongly disagree $; 2=$ disagree $; 3=$ slightly disagree $; 4=$ slightly agree $; 5=$ agree; and $6=$ strongly agree. An overall mean was calculated to represent respondents' subjective knowledge. The internal reliability estimate for this scale was $\alpha=.88$.

\section{Importance of Mosquito Control}

Mosquito control importance was measured using six items developed via a review of literature to identify the most frequently cited reasons for why controlling mosquito populations is important (e.g. "controlling mosquito populations is important because it protects residents from mosquito-borne illnesses"). Responses were collected using the previously mentioned six-point Likert scale of agreement. An overall mean was computed to represent respondents' perceived importance of mosquito control. The internal reliability estimate for this scale was $\alpha=.82$

\section{Personal Responsibility}

Personal responsibility was assessed using a single item with a six-point ordinal response scale $(1$ = strongly disagree; 6 = strongly agree $)$. Respondents were asked to indicate their degree of 
agreement with the following statement: "controlling the mosquito population in Florida is my responsibility." Test-retest reliability measures revealed no significant differences between respondents' pre- and post-test scores, $t(45)=-2.07, p=.06$.

\section{Demographic Characteristics}

The final section of the questionnaire was used to describe the demographic and personal characteristics of the respondents. Of the items in this section, three ordinal variables and one dichotomous variable were used for inferential analysis, including education, income, type of residence, and home ownership.

\section{Data Analysis}

Data for objectives one and two were analyzed and reported using descriptive statistics. For research objective three, Spearman Rho correlations were used to examine relationships between ordinal variables, bivariate correlations using Pearson's $r$ were employed to examine relationships between interval variables, and bi-serial correlations were used for relationships between dichotomous and ordinal variables (Field, 2013). The correlations were interpreted using the following guidelines: $.01 \geq \mathrm{R} \geq .09=$ negligible; $.10 \geq \mathrm{R} \geq .29=10 \mathrm{w} ; .30 \geq \mathrm{R} \geq .49=$ moderate; $.50 \geq \mathrm{R} \geq .69=$ substantial, $\mathrm{R} \geq .70=$ very strong (Davis, 1971).

\section{Results}

\section{Objective One}

Objective one sought to describe the public's information search behaviors in terms of search information search frequency, likeliness of source use, and perceived trustworthiness of sources. When asked how frequently they had sought information about mosquitoes or mosquito control topics, most respondents $(f=358 ; 71.8 \%)$ reported they had either never or rarely sought such information over the past year (see Table 2).

\section{Table 2}

Respondents' Search Frequency for Information About Mosquitoes or Mosquito Control Topics Over the Past Year

\begin{tabular}{lcc}
\hline Search Frequency & $f$ & $\%$ \\
\hline Never & 165 & 33.1 \\
Rarely (1-2 times) & 193 & 38.7 \\
Occasionally (3-4 times) & 97 & 19.3 \\
Often (5-6 times) & 22 & 4.6 \\
Very often (more than 6 times) & 23 & 4.6 \\
\hline
\end{tabular}

Regarding the sources they would use if they were to seek information, respondents selfreported being more likely to use local mosquito control program websites $(M=3.87 ; S D=$ 1.09), Centers for Disease Control and Prevention (CDC) websites ( $M=3.82 ; S D$ 1.13), and Florida Department of Health $(\mathrm{DOH})$ websites $(M=3.78 ; S D=1.16$; see Table 3$)$. Respondents 
were least likely to use University of Florida (UF/IFAS) Extension social media pages $(M=$ $3.14 ; S D=1.32)$ and social media posted by friends or family members $(M=2.85 ; S D=1.29)$ if they were to seek information about mosquitoes or mosquito control topics (see Table 3 ).

\section{Table 3}

Respondents' Likeliness of Use of Sources for Information About Mosquitoes or Mosquito Control

\begin{tabular}{|c|c|c|c|}
\hline Information Source & $M$ & $S D$ & Interpretation \\
\hline Local mosquito control program websites & 3.87 & 1.09 & Likely \\
\hline CDC websites & 3.82 & 1.13 & Likely \\
\hline Florida DOH websites & 3.78 & 1.16 & Likely \\
\hline $\begin{array}{l}\text { Websites about mosquitoes/mosquito control } \\
\text { topics ending in ".org" }\end{array}$ & 3.67 & 1.16 & Likely \\
\hline County government websites & 3.65 & 1.14 & Likely \\
\hline Websites about mosquitoes ending in ".com" & 3.50 & 1.19 & $\begin{array}{l}\text { Neither likely nor } \\
\text { unlikely }\end{array}$ \\
\hline UF/IFAS Extension websites & 3.49 & 1.18 & $\begin{array}{c}\text { Neither likely nor } \\
\text { unlikely }\end{array}$ \\
\hline $\begin{array}{l}\text { Local mosquito control program social media } \\
\text { pages }\end{array}$ & 3.41 & 1.33 & $\begin{array}{c}\text { Neither likely nor } \\
\text { unlikely }\end{array}$ \\
\hline CDC social media pages & 3.39 & 1.31 & $\begin{array}{l}\text { Neither likely nor } \\
\text { unlikely }\end{array}$ \\
\hline Local pest control company websites & 3.37 & 1.18 & $\begin{array}{l}\text { Neither likely nor } \\
\text { unlikely }\end{array}$ \\
\hline Florida DOH social media pages & 3.32 & 1.29 & $\begin{array}{l}\text { Neither likely nor } \\
\text { unlikely }\end{array}$ \\
\hline Friends or family members & 3.21 & 1.18 & $\begin{array}{c}\text { Neither likely nor } \\
\text { unlikely }\end{array}$ \\
\hline University of Florida social media pages & 3.14 & 1.32 & $\begin{array}{l}\text { Neither likely nor } \\
\text { unlikely }\end{array}$ \\
\hline $\begin{array}{l}\text { Social media posted by friends or family } \\
\text { members }\end{array}$ & 2.85 & 1.29 & $\begin{array}{l}\text { Neither likely nor } \\
\text { unlikely }\end{array}$ \\
\hline
\end{tabular}

Note: Real Limits: 1.00 to $1.50=$ very unlikely; 1.51 to $2.50=$ unlikely; 2.51 to $3.50=$ neither likely nor unlikely; 3.51 to $4.50=$ likely; 4.51 to $5.00=$ very likely.

Of the sources listed, respondents perceived CDC websites $(M=4.27 ; S D=.77)$ and Florida DOH websites $(M=4.22 ; S D=.77)$ as the most trustworthy (see Table 4). Communication with friends and family members $(M=3.30 ; S D=.99)$ and social media posted by friends or family members $(M=3.08 ; S D=1.11)$ were perceived by respondents as the least trustworthy of the sources of information. 


\section{Table 4}

Respondents' Perceived Trustworthiness of Sources for Information About Mosquitoes or Mosquito Control Topics

\begin{tabular}{|c|c|c|c|}
\hline Information Source & $M$ & $S D$ & Interpretation \\
\hline CDC websites & 4.27 & .77 & Trustworthy \\
\hline Florida DOH websites & 4.22 & .77 & Trustworthy \\
\hline UF/IFAS Extension websites & 4.09 & .86 & Trustworthy \\
\hline Local mosquito control program websites & 4.09 & .79 & Trustworthy \\
\hline County government websites & 4.05 & .84 & Trustworthy \\
\hline Websites about mosquitoes ending in ".org" & 3.97 & .80 & Trustworthy \\
\hline CDC social media pages & 3.90 & .96 & Trustworthy \\
\hline Florida DOH social media pages & 3.80 & .95 & Trustworthy \\
\hline University of Florida social media pages & 3.77 & 1.00 & Trustworthy \\
\hline $\begin{array}{l}\text { Local mosquito control program social media } \\
\text { pages }\end{array}$ & 3.75 & .98 & Trustworthy \\
\hline Local pest control company websites & 3.60 & .93 & Trustworthy \\
\hline Websites about mosquitoes ending in ".com" & 3.57 & .86 & Trustworthy \\
\hline Friends or family members & 3.30 & .99 & $\begin{array}{l}\text { Neither trustworthy } \\
\text { nor untrustworthy }\end{array}$ \\
\hline $\begin{array}{l}\text { Social media posted by friends or family } \\
\text { members }\end{array}$ & 3.08 & 1.11 & $\begin{array}{l}\text { Neither trustworthy } \\
\text { nor untrustworthy }\end{array}$ \\
\hline
\end{tabular}

\section{Objective Two}

Objective two was to describe the Florida public's subjective (i.e. self-perceived) and objective (i.e. actual) knowledge about mosquitoes and mosquito control topics. Responses were collected using a 6-point Likert-type scale and real limits were set for interpretation of responses: 1.00 to $1.50=$ strongly disagree $; 1.51$ to $2.50=$ disagree $; 2.51$ to $3.50=$ slightly disagree $; 3.51$ to $4.50=$ slightly agree; 4.51 to $5.50=$ agree; and 5.51 to $6.00=$ strongly agree. The mean score for respondents' subjective knowledge was $4.19(S D=.99)$. Respondents' objective knowledge scores ranged from 6.00 to 22.00 , with a mean score of $15.85(S D=3.01)$. The maximum possible score for the objective knowledge assessment was 22 .

\section{Objective Three}

Research objective three was to examine relationships between respondents' information search frequency, their subjective and objective knowledge, perceived importance of mosquito control, personal responsibility for mosquito control, and personal characteristics. Significant relationships were observed between respondents' search frequency and their subjective knowledge $r_{\mathrm{s}}(476)=.39, p<.000$; objective knowledge $r_{\mathrm{s}}(476)=-.15, p=<.01$; perceived importance of mosquito control $r_{\mathrm{s}}(476)=.14, p=<.01$; and perceived personal responsibility for mosquito control $r_{\mathrm{s}}(476)=.23, p=<.001$. Significant relationships were also observed between 
respondents' search frequency and two personal characteristics, including levels income $r_{\mathrm{s}}(476)$ $=.14, p<.01$ and education $r_{\mathrm{s}}(476)=.15, p=<.01$ (see Figure 2). No statistically significant differences were observed between search frequency and the personal characteristics homeownership and type of residence. Further exploratory analyses revealed significant relationships between personal responsibility and homeownership $r_{\mathrm{pb}}(474)=.15, p=<.01$ and type of residence $r_{\mathrm{s}}(474)=.15, p=<.01$. A significant and positive relationship between subjective and objective knowledge was also observed $r(500)=.13, p=<.01$ (see Figure 2).

\section{Figure 2}

\section{Results of Correlational Analyses of Relationships Between Variables}

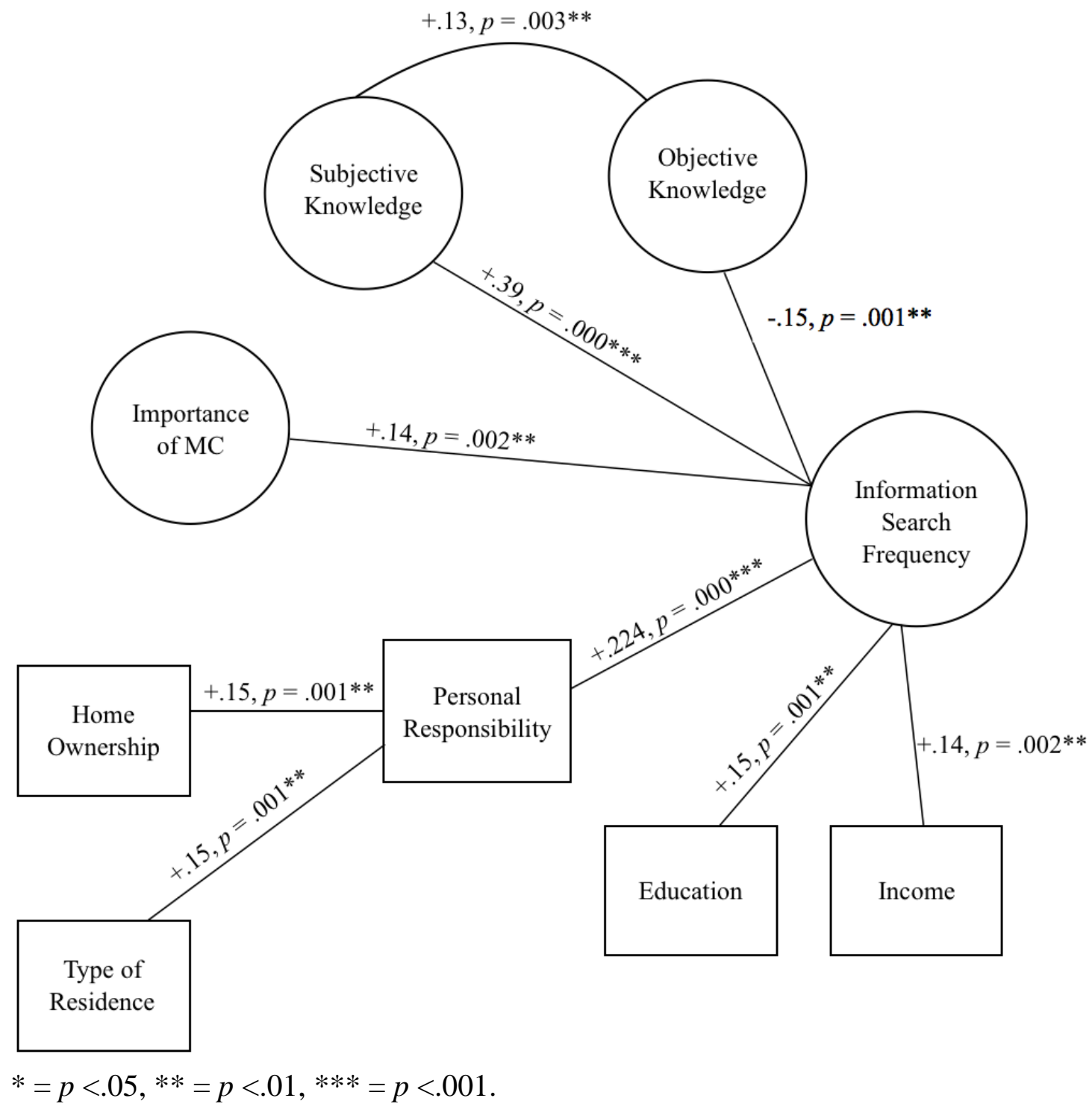




\section{Conclusions}

Nearly three-fourths of respondents had either never or rarely sought information about mosquitoes or mosquito control topics over the course of the year prior to the time this study was conducted. Further exploration of respondents' information search frequency about mosquito control revealed search frequency was significantly and positively associated with respondents' subjective knowledge, perceived importance of mosquito control, perceived personal responsibility for mosquito control, and income and education levels. While home ownership and type of residence were not directly correlated with search frequency, significant relationships were observed between these two variables and personal responsibility. Objective knowledge was negatively associated with search frequency. Lastly, respondents self-reported being most likely to utilize mosquito control program websites if they were to seek information about mosquito control topics, and they identified CDC and Florida DOH websites as the most trustworthy of the information sources listed.

\section{Discussion, Implications, and Recommendations}

Overall, the findings of the current study suggest members of the Florida public are not active seekers of information about mosquitoes and mosquito control topics. As such, Florida mosquito control districts' communication and education professionals should give considerable attention to best methods of reaching passive audiences when designing and delivering messages or announcements, outreach programs, or educational campaigns. Such methods should go beyond sharing information on mosquito control programs' websites to include additional efforts, such as launching neighborhood-wide campaigns, public forums, community peer-educators, primaryand secondary-level education programs, mobile phone applications, or other methods targeted to residents not actively seeking key information about mosquito control (Healy et al., 2014; Bodner et al., 2016; Paixão et al., 2019). Social media pages, though not typically high-ranked in terms of perceived trustworthiness, may also be particularly useful in reaching the large number of passive information-seeking respondents. It should be noted, however, that findings regarding the effectiveness of the previously mentioned methods remain mixed (Brewer \& Ley, 2013; Paixão et al., 2019), and future research is needed to examine best methods of engaging and communicating scientific information to passive audiences (American Association for the Advancements of Science (2017a; 2017b).

Communication and outreach efforts should also be designed to enhance residents' perceived importance of mosquito control, as well as foster their sense of personal responsibility in helping to control mosquito populations in their communities. The findings of the current study suggest doing so may enhance the likeliness residents will actively seek information in the future. The findings of this study also suggest home ownership and type of residence influence residents' perceived personal responsibility, in that those who own their own home or have homes with a yard have a stronger sense of personal responsibility in the matter. As such, it is recommended that outreach efforts be designed according to homeownership and type of residence. For example, it may be necessary to tailor messages to apartment owners/renters that illustrate the role they play in controlling mosquito populations in their area. Considering the positive association between search frequency and income and educational attainment, tailored efforts are also needed to engage residents of low-income areas who are less likely to actively seek out important information about mosquito control. 
Because respondents identified mosquito control websites as the sources they would most likely use if they were to actively seek information, mosquito control programs should continue to regularly post and update information on their websites. It should be noted that respondents' likeliness of use for most of the sources listed fell within the real limits of "neither likely nor unlikely." Considering respondents were not active seekers of information about mosquitoes or mosquito control, they may not hold strong opinions or preferences regarding the sources they would use because they are not interested in obtaining such information. Further research is needed to explore likeliness of source use among passive receivers of information. Local mosquito control districts should also include easily accessible CDC or DOH resources and links on their websites to direct residents seeking information to additional information they feel they can trust. Ezezika and Mabeya (2014) maintained such practice may help engage the end user and help establish and foster trust. It may also be beneficial for local mosquito control districts to reference the $\mathrm{CDC}$ or $\mathrm{DOH}$ when directly sharing information to the public via alternative methods to provide further credibility and increase public use (Brewer \& Ley, 2013; Robson \& Robinson, 2012).

Future research should be conducted to further examine the conceptual model presented to identify predictability and directionality of paths between the variables examined in this study. Research of this nature should also examine the potential moderating effect of home ownership and type of residence on the relationship between perceived responsibility and search frequency, as well as the interaction between objective and subjective knowledge in predicting search behaviors. The correlations between information search frequency and other variables in this study were low; however, prior research and theory suggest strong, predictive relationships between the variables examined. Further exploration of alternative or modified instrument measures of the variables included in this study may be beneficial to the development and assessment of future, predictive models.

\section{References}

American Association for the Advancement of Science. (2017a). Communicating science online. https://www.aaas.org/programs/center-public-engagement-science-andtechnology/communicating-science-online

American Association for the Advancement of Science. (2017b). Communication fundamentals. https://www.aaas.org/resources/communication-toolkit/communicationfundamentals\#Messages

The American Mosquito Control Association. (2018a). Control. https://www.mosquito.org/page/control

The American Mosquito Control Association. (2018b). Why we need mosquito control. https://www.mosquito.org/page/mosquitocontrol

Association of State and Territorial Health Officials. (2018). Communicating about effective mosquito control. https://www.michigan.gov/documents/emergingdiseases/ASTHO_Communication_3954 54_7.pdf

Baker, R., Brick, J. M., Bates, N.A., Battaglia, M., Couper, M.P., Dever, J. A., ... \& Tourangeau, R. (2013). Report of the AAPOR task force on non-probability sampling. American Association for Public Opinion Research. 
https://www.aapor.org/AM/Template.cfm?Section=Reports1\&Template=/CM/ContentDi splay.cf $m \&$ ContentID $=5963$

Bodner, D., LaDeau, S. L., Biehler, D., Kirchoff, N., \& Leisnham, P. T. (2016). Effectiveness of print education at reducing urban mosquito infestation through improved resident-based management. PLOS ONE, 11(5), Article e0155011. https://doi.org/10.1371/journal.pone.0155011

Brewer, P. R., \& Ley, B. L. (2013). Whose science do you believe? Explaining trust in sources of scientific information about the environment. Science Communication, 35(1), 115137. https://doi.org/10.1177/1075547012441691

Case, D. O. (2007). A survey of research on information seeking, needs, and behaviors. Elsevier.

Colton, D., \& Covert, R. (2007). Designing and constructing instruments for social research and evaluation. Jossey-Bass.

Connelly, C. R. (2016). Hurricanes and mosquitoes. Florida Cooperative Extension Service Electronic Data Information Source, Article ENY719. https://edis.ifas.ufl.edu/in535

Davis, J. (1971). Elementary survey analysis. Prentice Hall.

Duman-Scheel, M., Eggleson, K. K., Achee, N. L., Grieco, J. P., \& Hapairai, L. K. (2018). Mosquito control practices and perceptions: An analysis of economic stakeholders during the Zika epidemic in Belize, Central America. PLOS ONE, 13(7), Article e0201075. https://doi.org/10.1371/journal.pone.0201075

Ezezika, O., \& Mabeya, J. (2014). Improving communications in agbiotech projects: Moving toward a trust-centered paradigm. Journal of Applied Communications, 98(1), 38-44. https://doi.org/10.4148/1051-0834.1076

Field, A. (2013). Discovering statistics using IBM SPSS statistics. SAGE Publications, Inc.

Fonseca, D. M., Unlu, I., Crepeau, T., Farajollahi, A., Healy, S. P., Bartlett-Healy, K., Strickman, D., Gaugler, R. Hamilton, G., Kline, D., \& Clark, G. G. (2013). Area-wide management of Aedes albopictus part 2: Gauging the efficacy of traditional integrated pest control measures against urban container mosquitoes. Pest Management Science, 69(12), 1351-1361. https://doi.org/10.1002/ps.3511

Gubler, D. J., \& Clark, G. G. (1996). Community involvement in the control of Aedes aegypti. Acta Tropica, 61(2), 169-179. https://doi.org/10.1016/0001-706x(95)00103

Healy, K., Hamilton, G., Crepeau, T., Haly, S., Unlu, I. Farojollahi, A., \& Fonseca, D. M. (2014). Integrating the public in mosquito management: Active education by community peers can lead to significant reduction in peridomestic container mosquito habitats. PLOS ONE, 9(9), Article e108504. https://doi.org/10.1317/journal.pone.0108504

Johnson, E. J., \& Tversky, A. (1983). Affect, generalization, and the perception of risk. Journal of Personality and Social Psychology, 45(1), 20-31. https://doi.org/10.1037/00223514.45.1.20

Kalton, G., \& Flores-Cervantes, I. (2003). Weighting methods. Journal of Official Statistics, $19(2), 81-97$. http://www.sverigeisiffror.scb.se/contentassets/ca21efb41fee47d293bbee5bf7be7fb3/wei ghting-methods.pdf

Lamm, A. J., \& Lamm, K. W. (2019). Using non-probability sampling methods in agricultural and extension education research. Journal of International Agricultural and Extension Education, 26(1), https://doi.org/10.5191/jiaee.2019.26105 
National Academies of Sciences, Engineering, and Medicine. (2016). Communicating science effectively: A research agenda. The National Academies Press. https://doi.org/10.17226/23674

National Science Board. (2016). Science and technology: Public attitudes and understanding. In Science and engineering indicators (pp. 7.1-7.101). National Science Foundation. https://www.nsf.gov/statistics/2016/nsb20161/uploads/1/10/chapter-7.pdf

Paixão, M. M., Ballouz, T., \& Lindahl, J. F. (2019). Effect of education on improving knowledge and behavior for arboviral diseases: A systematic review and meta-analysis. American Journal of Tropical Medicine and Hygeine, 101(2), 441-447. https://doi.org/10.4269/ajtmh.19-0170

Priest, S. H., Bonfadelli, H., \& Rusanen, M. (2003). The "trust gap" hypothesis: Predicting support for biotechnology across natural cultures as a function of trust in actors. Risk Analysis, 23(4), 751-766. https://doi.org/.1111/1539-6924.00353

Qualtrics. (2019, April). ESOMAR 28 questions to help research buyers of online samples. https://www.iup.edu/WorkArea/linkit.aspx?LinkIdentifier=id\&ItemID=274179\&libID=2 74203

Rey. J. R., \& Connelly, C. R. (2016). Florida container mosquitoes. Florida Cooperative Extension Service Electronic Data Source, Article ENY860. https://edis.ifas.ufl.edu/in851

Radecki, C. M., \& Jaccard, J. (1995). Perceptions of knowledge, actual knowledge, and information search behavior. Journal of Experimental Social Psychology, 31(2), 107138. https://doi.org/10.1006Fjesp.1995.1006

Richards, S. L., Ghosh, S. K., Zeichner, B. C., \& Apperson, C. S. (2008). Impact of source reduction on the spatial distribution of larvae and pupae of Aedes albopictus (Diptera: Culicidae) in suburban neighborhoods of a Piedmont community in North Carolina. Journal of Medical Entomology, 45(4), 617-628. https://doi.org/10.1603/00222585(2008)45

Robson, A., \& Robinson, L. (2012). Building on models of information behavior: Linking information seeking and communication. Journal of Documentation, 66(2), 169-193. https://doi.org/10.10.1108/00220411311300039

Rose, R. (2001). Pesticides and public health: Integrated methods of mosquito management. Emerging Infectious Diseases, 7(1), 17-23. https://doi.org/10.3201/eid0701.010103

Takahashi, B., \& Tandoc, E. C. (2015). Media sources, credibility, and perceptions of science: Learning about how people learn about science. Public Understanding of Science, 25(6), 647-690. https://doi.org/10.1177/0963662515574986

Twyman, J. (2008). Getting it right: Yougov and online survey research in Britain. Journal of Elections, Public Opinions and Parties, 18, 343-354. https://doi.org/10.1080/17457280802305169

U.S. Environmental Protection Agency. (2012). Joint statement on mosquito control in the United States. https://www.epa.gov/mosquitocontrol/joint-statement-mosquito-control$\underline{\text { united-states }}$

World Health Organization. (2017). Vector-borne diseases [Factsheet]. https://www.who.int/en/news-room/fact-sheets/detail/vector-borne-diseases 